\title{
Learning by teaching in engineering: a step beyond learning by doing
}

\author{
Miguel Romá \\ Signals, Systems and Telecommunication Group. University of Alicante \\ Spain
}

\section{Introduction}

Engineering education has usually been carried out by engineers with a solid technical background but with little or no teaching background (at least at the beginning of our respective teaching careers). As a result, aside from didactic theories, the docent models used in engineering schools have been transferred from teacher to learner for years. Notwithstanding, this situation has dramatically evolved in the last decade, and engineering education is undergoing a profound process of change. Some of the most common issues concerning engineering training are those related to active learning environments. The main goal of our task as educators is to provide students with an environment in which learning may occur. Even though active learning is not a new trend in engineering education, different schemes based on learning by doing are being proposed every day. Nevertheless, by itself, 'doing' can not ensure effective learning. Further reflection of what has been done and why is compulsory in order to effectively transform the information into knowledge. Moreover, as stated by Phil Race in his "ripples model" (Race, 2005), the following five factors appear to be involved in successful learning: wanting to learn, needing to learn, learning by doing, learning through feedback and making sense (or digesting). Designing learning experiences based on these five elements will become a base for strong learning opportunities.

Teaching a new topic, or course, for the very first time is a profound learning situation in which all five factors are present. Any educator will agree that they considered her or his first classes as a high-level learning situation. Besides, within this teaching environment, assessment provides valuable generation of feedback and digesting ripples. Allowing students to be involved in such an environment will offer a favourable and very effective learning opportunity for both trainer and trainee. Although the role of teaching as an efficient learning activity is not a new trend which recently appeared in modern Didactics researches, teaching anything to anyone can also be understood as an active learning activity. In fact, the roman philosopher Lucius Annaeus Seneca stated Docendo discimus (by teaching, we learn) in his Epistulae Morales and Lucilium, written at the end of his life in the middle of the first century. The use of teaching as a learning strategy has been applied in formal courses throughout history, especially from the end of the 19th century until today. 
Moreover, used as a tool in autonomous learning, the test of whether or not one really understands a concept is by trying to teach it to someone else (Rusczyk, 2008).

When designing the sequence of activities for any engineering course, especially in active learning environments, the generation of opportunities of peer teaching to take place can add extra value by provoking learning within students. The way of putting this into practice in an engineering course designed into an active learning scheme will be described, as well as how the course designing process can efficiently be transferred to other courses. With these principles in mind, a course previously adapted to an active learning environment has been reshaped to let the teaching experience take place as a learning situation. Course activities are designed so that some of the students act, at certain moments, as trainers of a group, and their colleagues as trainees. Roles change at different activity stages so that all students have the opportunity to be the trainer at some stage. In terms of assessment, students will have the opportunity of getting feedback and digesting by means of peer and self assessment.

Working on a particular course designed for an active learning environment, including learning by teaching, will achieve, not only academic, but transversal skills improvement. Issues such as group working, communication skills or liability are managed as well as engineering or scientific skills. After a five year process of adaptation of the learning model for the "Video Engineering" course from conventional to active style, a considerable set of activities have been generated. Furthermore the possibility of exporting any particular activity or sequence of activities to other disciplines will provide a wider range of benefits, promoting improvement in other such courses. The design process, developed to generate activities, has been carried out to provide other professors an easy way to adapt one particular activity, or a sequence of activities, focused on Video Engineering to their own disciplines. Although Video Engineering is a compulsory third year course, single activities or sequences of activities have been exported to first and third year courses, both compulsory and optional. The main interest of the project was the exchange of activities between courses within the Telecommunication Engineering degree, but the final results were also extended to the Computer Science degree.

The Chapter is structured as follows: Section 2 presents a historical overview and some formal and well-established approaches of the use of teaching as a learning tool. The aim is not to be exhaustive but to analyze some examples of how teaching is being used and which are the outcomes of its use in the learners. In section 3 the courses "Video Engineering" and "Video Laboratory", in which the methodology has mainly been used, will be described. This is followed by a closer look at the specific teaching opportunities generated in section 4 , and to finish there will be a presentation of the results and conclusion of the project.

\section{The role of teaching in the learning process}

Besides the ancient references to teaching as a way of learning cited in Section 1, the birth of teaching as a system in the learning process can be the "Monitorial System" or "Mutual Instruction System" developed by the work of Andrew Bell and Joseph Lancaster during the early 19th century. The method was based on the use of students playing the role of helpers to the teacher (Graves 1922). The method was used by 19th century educators in England and Wales. The same idea was transferred to France under the name of "écoles mutuelles" (Querrin, 2005). The main and praiseworthy reason laying down these first movements can 
be found in the so called Philantropy in Education (Graves, 1922). The goal of numerous movements in the 18th century was to provide education to poor children, with the result of the need of far more teachers than those available. To get up to 300 pupils for one teacher, the only possible way was to train students to help in the teaching process. Figure 1 is an illustration of the "Monitorial System" in action from the Cyclopedia of Education (Monroe, 1915).

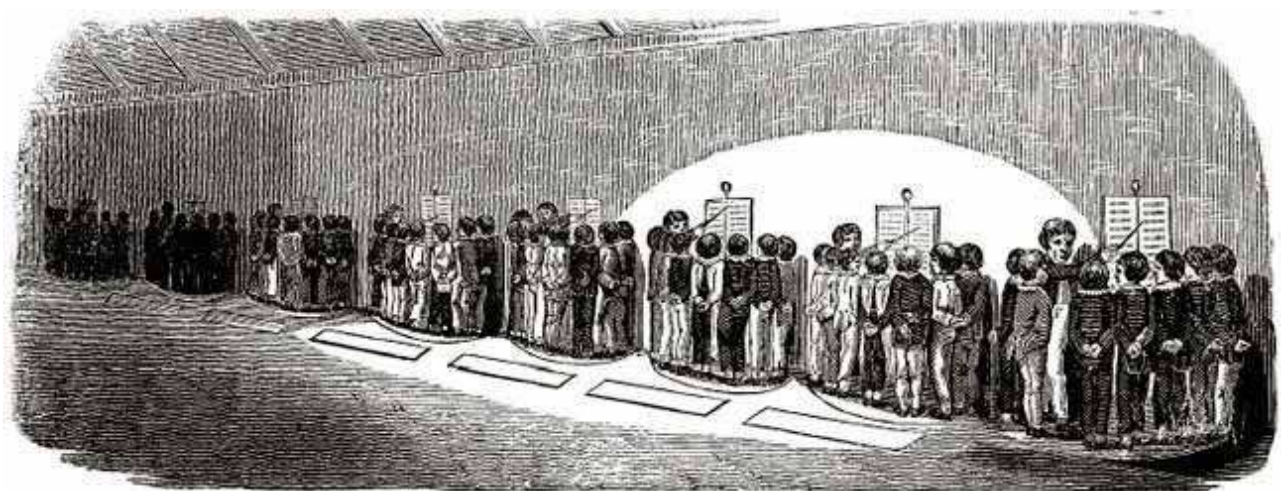

Fig. 1. Tutorial System in action (from "A Cyclopedia of Education", Monroe, 1915, not in copyright).

The use of teaching as a learning strategy really began at the end of the 19th century. Nevertheless, the method was supported by extensive research with the work of Jean-Pol Martin in the early eighties. The system developed by Martin is called LdL (Lernen durch Lehren, Learning by Teaching). LdL (Marin, 2002) was implemented as a systematic tool for the teaching of French as a foreign language. Martin found, and reported, that by turning the students into teachers he dramatically increased their motivation. They not only spoke far more in each class, as they also overcame their inhibitions more quickly. While the teacher remained the final expert, students assumed many of the other tasks which were formerly routinely and unnecessarily carried out by the instructor.

One variation of LdL, also applied to language teaching can be seen in (Grezega, 2006). One interesting quotation of Grzega is his suggestion of extending "Learning by Teaching" to "Learning by Teaching and Doing Research". However, also working in language courses, J. D. Skinner points out that LdL can be easily applied to university level courses of practically all sizes and in almost every subject (Skinner, 2002). One interesting outcome of Skinner's research is the ability developed by students to think critically and independently. This important intellectual ability is, after all, the goal of all university study.

One similar method has been implemented under the name "Learning Through Teaching" (Elmendorf, 2006), applied to science courses. The model gives students an opportunity to use what they are learning in a college classroom to develop curricula, and then teach those curricula in an elementary school. The evidence of the project showed that casting students in the role of teacher is a remarkable way of making visible, to both the students and their instructors, some invisible shortcomings of traditional educational approaches.

Going back to the Race "ripples model" as presented in Section 1, it is possible to find a more embedded role to teaching inside the learning process. Complementing the basic five 
factors, or ripples, underpinning profound learning situations (wanting, needing, doing, digesting, feedback), there are two more related ripples, teaching and assessing. Teaching, especially when it is done for the first time, yields high learning pay-off for teachers, as the five main ripples are present at the same time (Race, 2005). The students acting as explainers are benefiting from the high learning pay-off associated with teaching. Those which are being explained to (the "explainees", according to Race's terminology) are having a good deal too as they are having the subject explained by someone who remembers how he or she made sense of the subject. When thinking about assessing, it is easy to agree to consider it another learning situation. Therefore the assessment is introduced as one more ripple in the model.

Is it possible to think about teaching without considering any kind of assessment? While the majority of the modes focus their attention on students playing the role of explainers, the inclusion of the assessment is a key concept. In fact, aren't they two pieces of the same jigsaw? The main goal of the presented project is to provide teaching-assessing situations on different scales (small and big group, self and peer assessment) within engineering courses which were previously adapted to active learning schemes. Moreover, taking advantage of the design process in order to export activities to other engineering courses will also be a goal. Obviously, the colleagues responsible for these other courses must be motivated to promote changes towards active learning schemes. Another key question, in order to help colleagues' receptivity towards changing methodologies, will be to demonstrate that no special facility is needed to work in active group-based schemes. Notwithstanding, it is obviously desirable to have the opportunity to work in custom designed rooms.

\section{Context}

The environment in which the work is being carried out is a sequence of last year's courses called "Video Engineering" and "Video Laboratory". They are third year courses in Telecommunication Engineering (BSC), with sound and image speciality. Video Engineering is a compulsory course in the first semester, while the optional Video Laboratory course is its natural complement and takes place during the second semester. The duration of Video Engineering, as established in the curriculum, is six theory credits and three practical ones, with one credit considered as ten hours of face to face class time. The Video Laboratory course is led through 1.5 theory credits and 6 practical ones.

\subsection{Video Engineering structure}

Video Engineering is a discipline with a high degree of engineering based development. The course's main goal is formulated by one general objective: To train engineering work characteristics by means of studying video systems. Some of the competences explicity presented include group working, communication skills and complex problem analysis. Taking this goal into account, the course is suitable for using problem based learning (PBL) (Woods, 1994) boarding the different aspects as if students were engineers trying to find the answer of a particular technological problem. This is the approach of all the activities performed throughout the course, considering the imposition of slowly increasing their level of complexity.

The first idea was to organize the classroom into informal cooperative groups (Johnson et al., 1991). Making students sustain a rigid working structure, inside and outside the 
classroom, for the very first time, could lead to undesirable rejection. However, after a pilot course, it was seen that the groups remained unchanged throughout the course. Later, the choice was to employ formal groups, to be used both in theory and in laboratory sessions. Furthermore, during the first course weeks, special attention had to be paid to detect problems in the groups. The groups worked together to solve the questions of each session. In the last year, the whole group was divided into 22 small working groups of three or four people each. As the methodology basis is PBL, every group will complete the course with the same set of activities. These activities can be divided into two categories according to the time required by the students: minor and major activities. On the one hand, minor activites only take a portion of the class time whereas major activities are set to last several weeks. Both major and minor activities are designed in order to pose problems and situations to be solved using different engineering skills and transversal ones as well, despite their specific content. Therefore, it would be possible to define problems regarding other disciplines with a very similar scheme and treatment.

\subsubsection{Minor activities}

Most of the so called 'Minor activities' correspond to those of the PBL sequence into the development process of the syllabus. Cooperative groups have to solve the same problem in a limited amount of time, usually between 10 and 20 minutes (Figure 2).

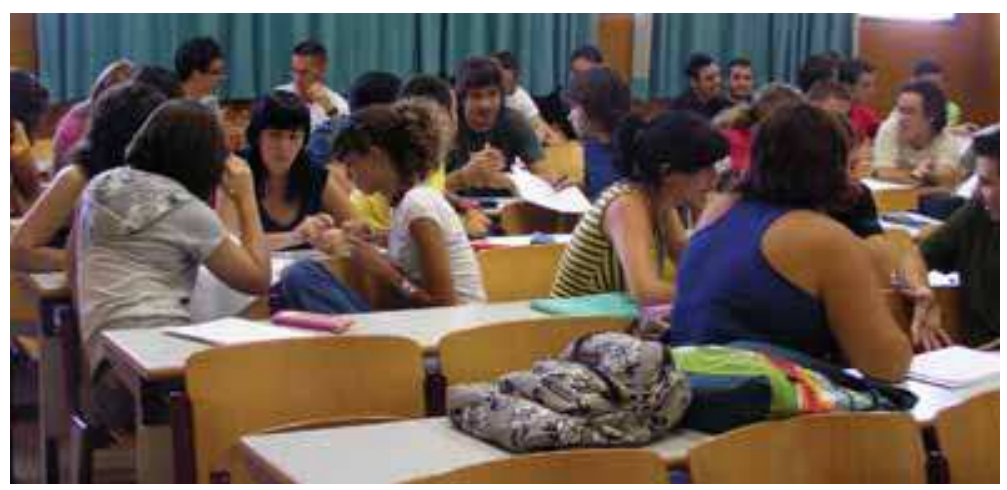

Fig. 2. Cooperative groups working on a minor activity during a generic theory session.

A set of special minor activites was designed to work on specific aspects of the engineering training process. In the final course timing, minor activites comprise of mainly three quarters of the course time, in both theory and laboratory sessions.

\subsubsection{Major activities}

As introduced in the previous chapter, minor activities take about three quarters of the course time. The rest of time is structured in the form of Major Activities. This time, working groups have to solve technological problems by their own, presented in the form of research projects. For this activity to succeed, it is necessary that the problem has sufficient impact on their technological everyday life and that the solution is not unique, but has different variants. The first requirement is relatively easy to achieve in a course like Video 
Engineering, but can also be found in other non-technological based courses. The second is a lot more difficult since students are not mature professionals that can manage a variety of engineering skills to solve such problems. All groups work towards solving the same problem but emphasizing that it is not a matter of competition for the best solution. In order to promote collaboration skills, groups are encouraged to interact with eachother and to try to discuss the advances from a technical point of view. The students work in (fig. 3) and out of the classroom and in the laboratory for about three weeks on each project.

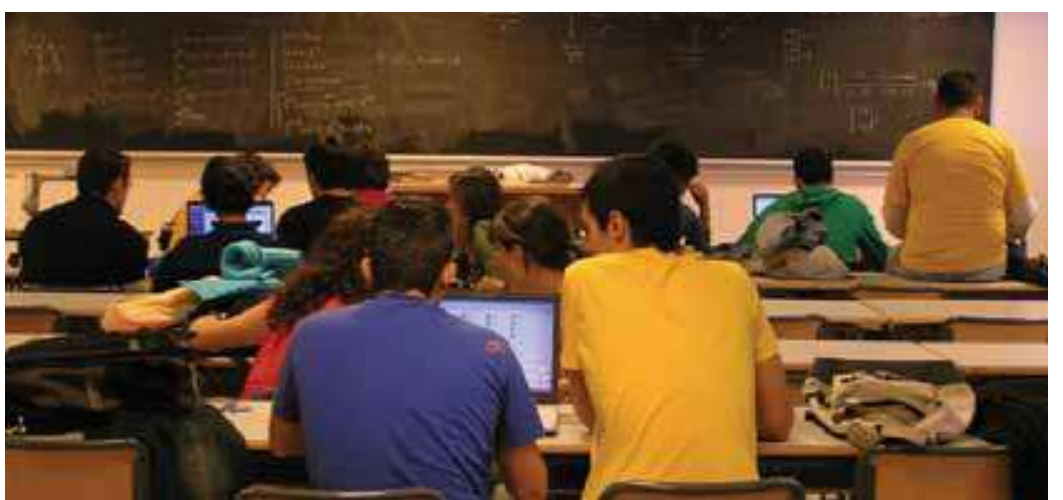

Fig. 3. Cooperative groups developing a major activity (research project) during a generic theory session.

The projects are designed according to some basic guides in order to ensure their success:

- The project must be a challenge in itself. It must be a complex problem with an open solution and be of real interest.

- Working on the project has to ensure reaching some of the knowledge objectives considered in the course, as it consumes class time.

- The possibility of findind a solution must be realistic, in order to avoid students' frustration. Besides, the project must include some really complex aspects presenting real challenges to the students.

\subsection{Video Laboratory structure}

The whole course takes place in the Television and Video Laboratory facility. The laboratory is equipped with 20 identical television training workstatiosn (Figure 4) and 8 different video engineering configurations (Figure 5). 


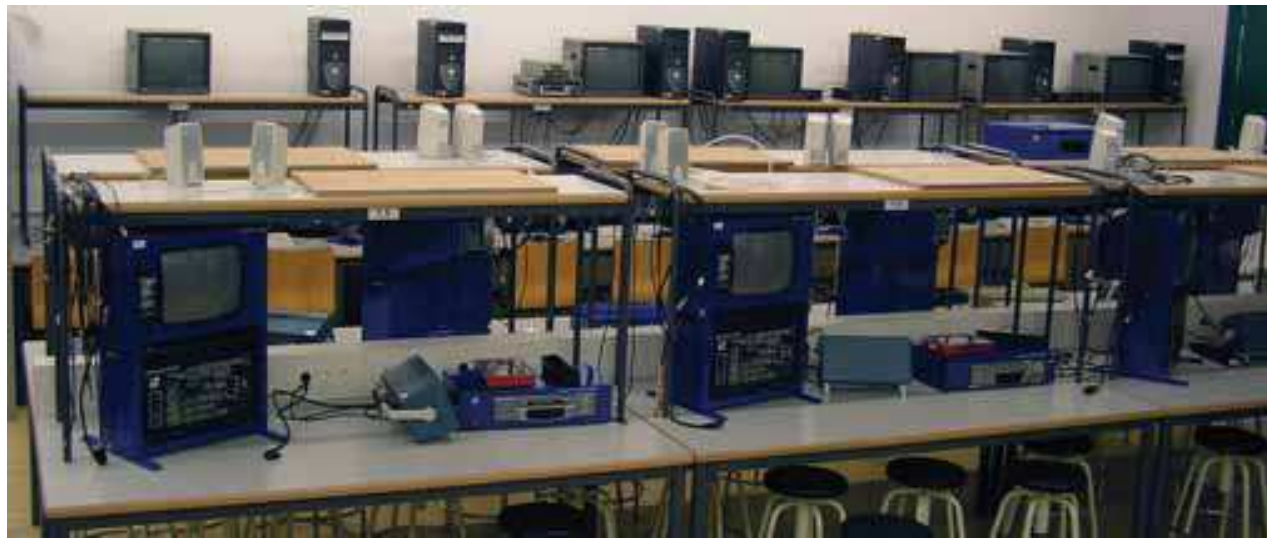

Fig. 4. General view of the Television and Video Laboratory.

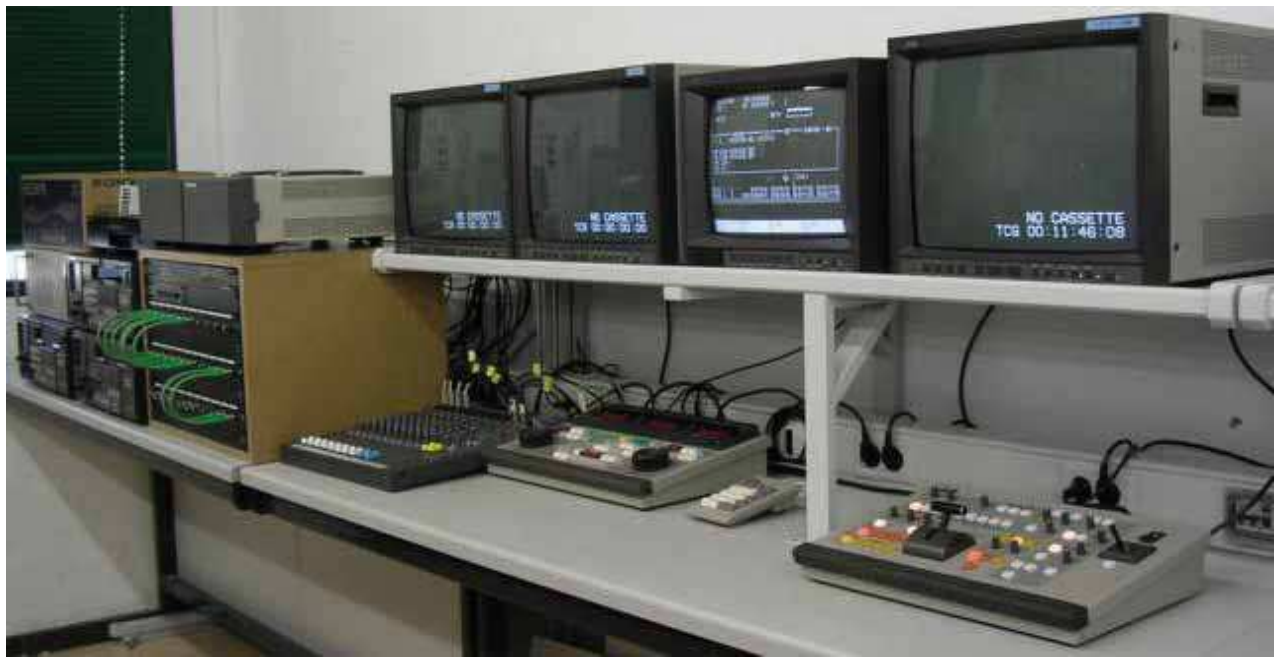

Fig. 5. Image of the tape-based digital editing system used in the Video Laboratory course.

Each of the different video engineering workstations is designed to train one specific aspect of the technical procedures performed in professional video production facilities. As the laboratory is equipped with high quality broadcast systems, it is not possible to have more than one working place for each configuration. The course is designed to put into practice the engineering skills trained in Video Engineering, and apply them to realistic working situations. A short description of the equipment available on each configuration can be found in Table 1.

The Video Laboratory course is structured in two two-hour practical sessions and a one hour theory session per week. Having just one working place of each of the stations listed in Table 1, the class has to be organized in working groups, shifting from one station to the next each week. As the theory session is also held in the laboratory, it is used to talk about 
specific aspects concerning course goals on students' request. Furthermore, every group develop a small research or industry-based project during the course.

\begin{tabular}{|c|l|l|}
\hline No & Name & Main equipment \\
\hline 1 & Broadcast digital camcorder & $\begin{array}{l}\text { Tape (D9 and DV) and hard disk drive } \\
\text { broadcast digital camcorders }\end{array}$ \\
\hline 2 & Linear A/B-Roll editing station & Digital tape-based D9 editing station \\
\hline 3 & Camera control unit & $\begin{array}{l}\text { Studio cameras, CCUs and technical control } \\
\text { system }\end{array}$ \\
\hline 4 & Video switching station & $\begin{array}{l}\text { Digital video switcher, titles station, digital tape- } \\
\text { based video recorder and player }\end{array}$ \\
\hline 5 & Audio-video measuring station & Audio coherence meter and video gamut meter \\
\hline 6 & $\begin{array}{l}\text { Digital video generation and } \\
\text { control }\end{array}$ & $\begin{array}{l}\text { Digital test pattern generator and multi-format } \\
\text { video measuring system }\end{array}$ \\
\hline 7 & Non-linear editing station & Dual monitor PC-based editing station \\
\hline 8 & Industrial production suite & MiniDV camcorder and editing station \\
\hline
\end{tabular}

Table 1. Overview of the configuration of video working stations used in Video Laboratory.

\section{Opportunities for teaching to take place}

Both courses presented in Section 3 were organized into an active learning scheme before considering the convenience of including teaching in courses design. Accordingly, one of the project goals was to include such situations within the previously designed sequence of activities. Trying to maximize the learning outcomes, the adaptation of teaching has to be implemented making all Race's ripples appear. Taking into account that ripples are related to each other, is not easy to make a direct assignment between activity and ripple. The only exception is the "learning by doing" ripple, as it is obviously generated when the methodology is active-based. With regard to the other ripples, a more generic approach is considered trying to fulfil the whole range. Teaching is not only the process of explaining something to someone else but a more complex situation including mature reflection periods.

The aim was to make students play a highly responsible role inside their own learning process. Trying to place students fully inside a teaching role, a set of activity categories has been included. Table 2 shows the major relationships between these activities and their foremost influence in generating the five main ripples compulsory for profound learning to take place: wanting to learn, needing to learn, learning by teaching, learning through feedback and digesting what has been learnt. Even though the crosses in Table 2 are not an exhaustive and rigid selection, they represent the main contribution of each activity to the ripples. For instance, letting students state course contents is related directly to the "wanting to learn" ripple, as they are selecting what they want to learn. It is also clearly related to "learning by doing" and to "digesting" as well, as there is the need of a reflection process to decide what to learn and why. But, if the activity is coherently designed, there will also be feedback. Moreover, if one is maturely deciding what to learn, there is an implicit "needing to learn", so all the five ripples will be inherently generated by any of the proposed 
activities. It is important to notice that each activity contributes to several ripples, and all the ripples appear several times.

\begin{tabular}{|l|c|c|c|c|c|}
\hline \multirow{2}{*}{\multicolumn{1}{|c|}{ Activity }} & \multicolumn{5}{c|}{ Ripple relationship } \\
\cline { 2 - 6 } & Wanting & Needing & Doing & Feedback & Digesting \\
\hline Stating course goals & $\mathrm{X}$ & $\mathrm{X}$ & $\mathrm{X}$ & & $\mathrm{X}$ \\
\hline Stating contents & $\mathrm{X}$ & & $\mathrm{X}$ & & $\mathrm{X}$ \\
\hline Teaching group mates & & $\mathrm{X}$ & $\mathrm{X}$ & & $\mathrm{X}$ \\
\hline Teaching whole course group & & $\mathrm{X}$ & $\mathrm{X}$ & & $\mathrm{X}$ \\
\hline Self assessment & & & $\mathrm{X}$ & $\mathrm{X}$ & $\mathrm{X}$ \\
\hline Teacher assessment & & & $\mathrm{X}$ & $\mathrm{X}$ & $\mathrm{X}$ \\
\hline Peers assessment & & & $\mathrm{X}$ & $\mathrm{X}$ & $\mathrm{X}$ \\
\hline
\end{tabular}

Table 2. Basic relationship between teaching activities and ripples generation.

The courses in which the main work was done include all types of activity with the exception of stating course goals which is only performed in Video Engineering. Taking into account that the laboratory equipment is fixed, it is difficult to deal with a different approach for which the laboratory is designed.

It may be understood that working in active learning environments makes it extremely easy to include teaching opportunities within the designed sequence of activities. Moreover, many such situations appear spontaneously in the normal development of common active learning schemes. Any group working on a common task involves peer teaching as well as peer assessment.

\section{Results}

Project results will be summarized in four categories: activities description, academic results, students' subjective opinion and migration to other courses or disciplines. Each of the following sub-sections includes one of these result categories.

\subsection{Activities description}

In this section, a short view of the activities related to the teaching role will be included. Whenever relevant it will be noted if the activity is used in the Video Engineering course, Video laboratory course or both. The activities are classified in three categories, according to different teaching situations: course design, explanation and assessment. Course design activities are the ones performed at the beginning of one particular course, with the intention of making students direct actors in the process of stating course goals, contents, methodology and so on.

\subsubsection{Course design-related activity}

One of the activities, more effective due to its deep impact in the needing, wanting and digesting ripples, is carried out during the first class day of the course. The main goal of the activity is to let students think about how to work to get a complete engineering training, 
and, as a consequence, to fix the objectives and the methodology suitable to reach them. Letting students decide what to do and how to do it avoids the necessity of artificially creating motivation. The whole activity is centerd around two questions:

- What could be the definition of Engineering?

- Which are the most important skills one must have to become an Engineer?

Even though seemingly obvious questions, there is a considerable amount of last year students who had not reflected upon them.

The activity combines individual, small group and whole group working stages, structured around the preparation of hand made posters with the answers to the two questions. A complete description of the activity can be found in (Romá, 2008). The result of the activity will be the selection of those 'compulsory skills to become an engineer' drawn up as course goals. Students' work will become course goals and their corresponding assessment elements. Taking into account that this is the only course fully organised following an active learning scheme, it is surprising how easily students change their role from passive to active actors. Figure 6 shows how the interaction between each other occurs naturally during the poster preparation.

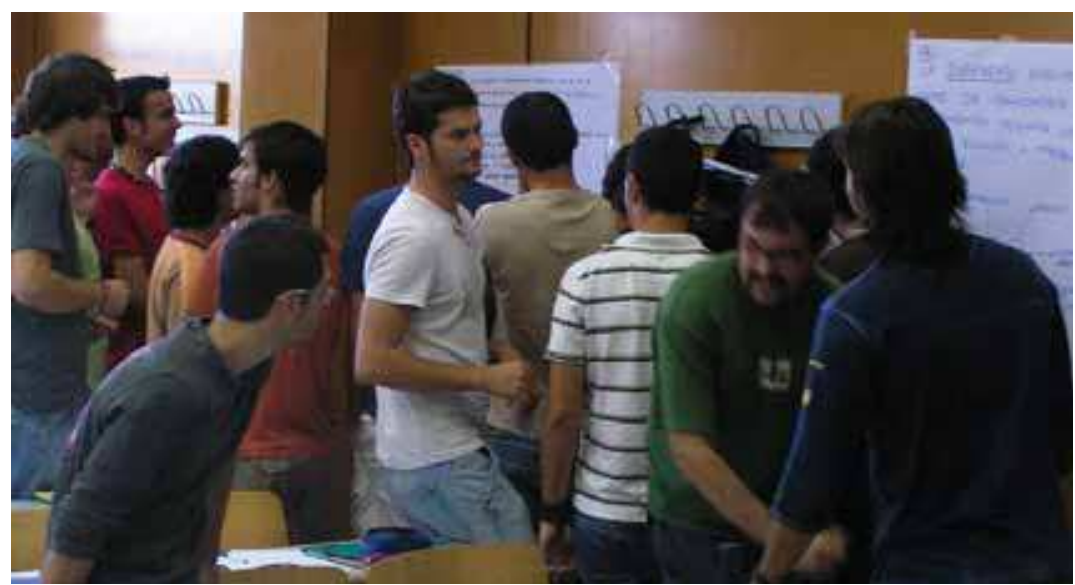

Fig. 6. Active students stating course goals during the firs day activity.

As introduced in Section 3.2, each working group has to carry out a short research project related to video technology. The particular content of these projects is freely chosen by group members. In this sense, students have the opportunity of focusing the effort on subjects of their particular interest. They are working on what they want to.

\subsubsection{Explaining-related activities}

Day by day Video Engineering course sessions are mostly employed in developing small group minor activities. To ensure the activity is completed in the available amount of time, each member has to play a different role within the group. As any of the group members has to be able to explain the solution they have obtained, it is compulsory to include peer to peer teaching inside the group. 
Major activities (research projects) carried out in both courses, end with a public presentation, which is delivered by one group member selected by the professor just before the presentation. This situation also demands peer to peer teaching inside the group. Furthermore, the presentation itself is considered as a teaching situation, as the whole group will have to understand its contents.

The organization of the Video Laboratory course leads to having each small group working in a different professional video configuration. There can be up to ten groups working in simultaneous and different working stations, depending on the number of students. Each group is provided with enough time to become expert in one of the configurations. In each session, a different group member is designated as tutor of the group working within the configuration which he or she is expert, providing a peer to peer teaching situation (Figure 7).

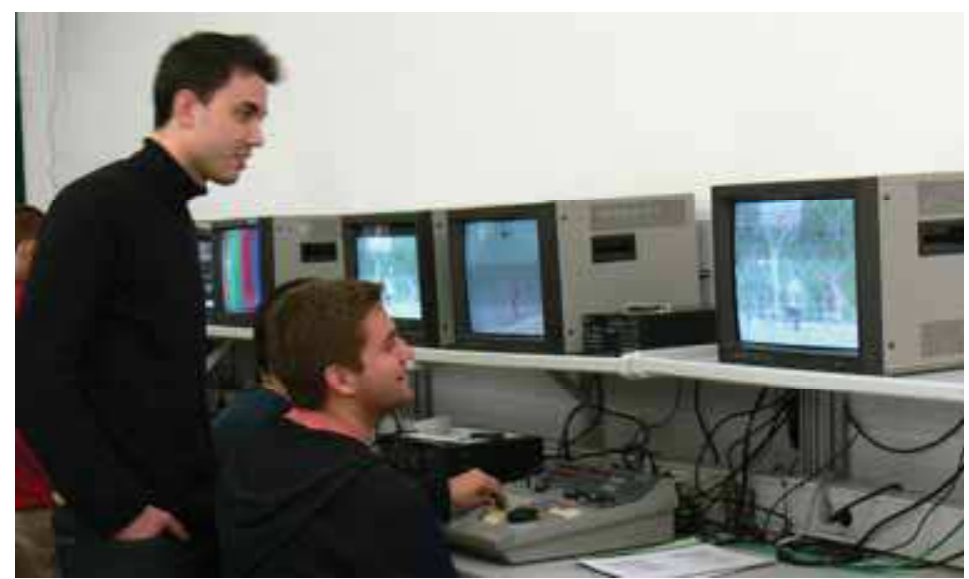

Fig. 7. Student acting as tutor in a Video Laboratory session.

\subsubsection{Assessing-related activities}

Evaluation procedures always generate mature reflection. Making students develop argued self and peer assessments, efficiently provides the generation of the feedback and digesting ripples.

Assessment by students in the Video Engineering course is carried out in three ways, self, peer and group. The problem based section of the course ends with the assessment of every working group performed by the group itself. Each group is asked to deliver a report based on its degree of course goals achievement. Each student also has to develop a similar report analyzing her or his behaviour. Peer assessment is used after the research projects' public presentations. Each group's project is evaluated by the rest of the whole group. The self assessment based on a reasoned form based on course goals and contents, is a useful tool in the generation of the "digesting" ripple. Moreover, the initial fear under self overrating vanished after the reading of the assessments. Some groups have even received feedback to resubmit their evaluation achieving with a higher final mark.

The assessment in Video Laboratory is carried out in a complementary way. On the one side, each tutor evaluates the performance of the group she or he has lead. On the other side, 
each group assesses the job of its designated tutor. In both cases, the submitted reports have to be justified according to course goals.

\subsection{Academic results}

The evolution of students' academic results can be used as an indicator of the outcomes provided by one particular methodology as long as the evaluation is correctly designed. Analyzing some academic data of the students over the last five years (period of adaptation into active learning scheme) can provide relevant information about the learning process. Under the hypothesis of a conveniently designed evaluation system, the final marks can reflect an overall view of the degree of learning goals achievement. Moreover, the drop-out ratio can be globally correlated with the motivation and implication of students in their own learning process (wanting and needing ripples).

The global academic results from course 2002-2003 to 2007-2008 are summarized in table 3. The first figures $(2002 / 2003)$ correspond to the last year the course followed a conventional methodology based on lectures, unconnected laboratory sessions and problem solving sessions. In the following years the methodology has been progressively adapted into an active learning scheme. Every new year specific aspects of the course design have been modified. The "Comments" row indicates the most significant modification introduced in the corresponding year. As the final mark is established in a 0-10 scale, the "Final mark" row represents the final average mark of all the students. Although a small group-based methodology pilot test was carried out on 2003, the figures show a significant improvement.

\begin{tabular}{|c|c|c|c|c|c|c|}
\hline Year & $\mathbf{0 2 / 0 3}$ & $\mathbf{0 3 / 0 4}$ & $\mathbf{0 4 / 0 5}$ & $\mathbf{0 5 / 0 6}$ & $\mathbf{0 6 / 0 7}$ & $\mathbf{0 7 / 0 8}$ \\
\hline Comments & $\begin{array}{c}\text { Conventional } \\
\text { methodology }\end{array}$ & Pilot test & $\begin{array}{c}\text { Theory } \\
\text { sessions } \\
\text { modified }\end{array}$ & $\begin{array}{c}\text { Lab. Sessions } \\
\text { modified }\end{array}$ & $\begin{array}{c}\text { Research } \\
\text { projects }\end{array}$ & $\begin{array}{c}\text { Teaching } \\
\text { situations }\end{array}$ \\
\hline Pass & $61,5 \%$ & $81 \%$ & $80 \%$ & $89 \%$ & $84 \%$ & $86 \%$ \\
\hline $\begin{array}{c}\text { Final mark - } \\
\text { Mean value } \\
\text { (0-10) }\end{array}$ & 5.0 & 5.6 & 5.5 & 5.8 & 5.7 & 6.9 \\
\hline Std. Dev. & 2.21 & 1.28 & 1.27 & 1.17 & 1.86 & 0.87 \\
\hline
\end{tabular}

Table 3. Global academic results from year 2002-2003 to 2007-2008.

Even though the general tendency of academic results provides better marks every year since the introduction of an active scheme, one significant increase can be noticed in the last analysed year. The introduction of specific teaching activities implies visible improvement in the final marks obtained by students, with a lower dispersion in results, as stated by a lower standard deviation. The rise in mean value is greater than one point and the standard deviation falls below one.

Figure 8 shows the evolution of the number of students abandoning the course from $2002 / 2003$ until 2007/2008. The general tendency is quite clear with a descending slope. The figures are especially interesting in the last three years, with an abandon rate lower than $10 \%$. As the active-based methodology began in 2003 , the number regarding the first year is obtained from the number of students not attending the final exam from the total of registered ones. The absolute values are 10 dropouts out of 48 students in 2003/2004, 7 out of 55 in 2004/2005, 7 out of 75 in 2005/2006, 4 out of 77 in 2006/2007 and 0 out of 63 in $2007 / 2008$. 


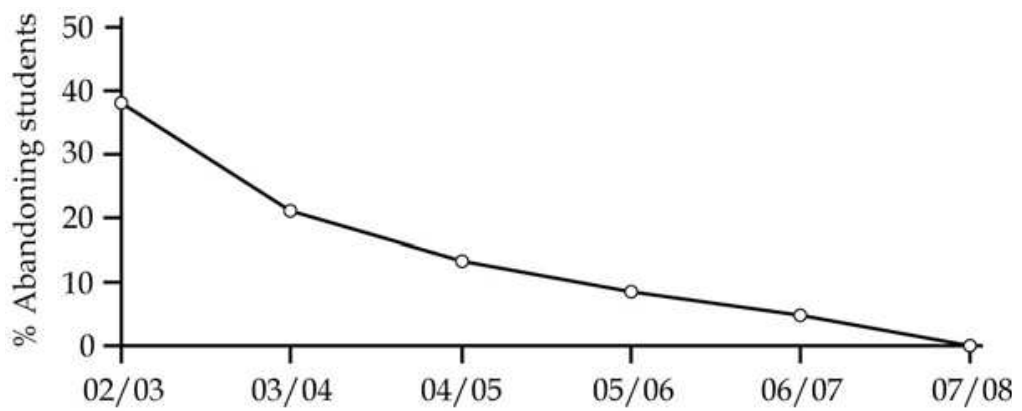

Academic year

Fig. 8. Evolution of the percentage of students abandoning the Video Engineering course from 2002 until 2008.

The analysis of the results in Figure 8 is relevant, in particular when comparing them with the number of dropouts that can be observed in similar courses of the same degree. It is not unusual to find more than $50 \%$ of students leaving courses, before the first half of the course is complete.

\subsection{Subjective opinions}

Two questionnaires were used as indicators of students' opinion related to course results. The first one was used at the University of Alicante to obtain the students' valuation of both courses and teachers. It was formed upon a series of ten questions in which " 0 " is the worst opinion and " 10 " the best. The results of the $2007 / 2008$ academic year are presented in Figure 9 (at the time of preparing these papers, the results of the present year were not yet available). Yellow bars correspond to course teacher results, blue bars to the mean value of the staff belonging to the same department and the green one to the mean of all professors teaching in the degree.

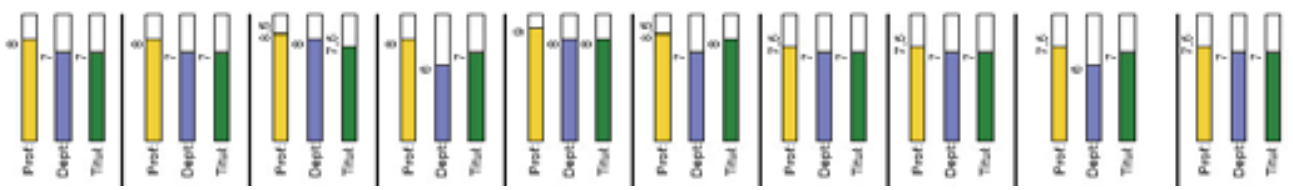

Fig. 9. Mean value of the questions from the standard course and teacher evaluation test used at the University of Alicante.

The second test was a custom made questionnaire, designed to obtain detailed information about the opinion the students have concerning subject treatment. Students were asked about their valuation of 23 specific aspects, as working in groups or developing research projects. The answers were on a 1-5 scale, in which 1 is the worst opinion and 5 the best. The mean results of this questionnaire can be observed in Figure 10. The questions marked with a downward arrow $(\downarrow)$ correspond to those one in which favourable opinion signifies a low answer. 
The most significant questions for the present study are numbers 1, 19, 20 and 22. Question 1 is "The general design of the course is", and the answers go from 1, meaning very bad to 5 , meaning very good. The mean value for this question was 4.5 . Questions 20 and 21 refer to course goals in the following terms: "I know course goals" and "I think course goals have been reached". The final values for these questions were 5 and 4 respectively. The whole course agrees on fully knowing goals, and the general impression about reaching them was of 4 out of 5 .

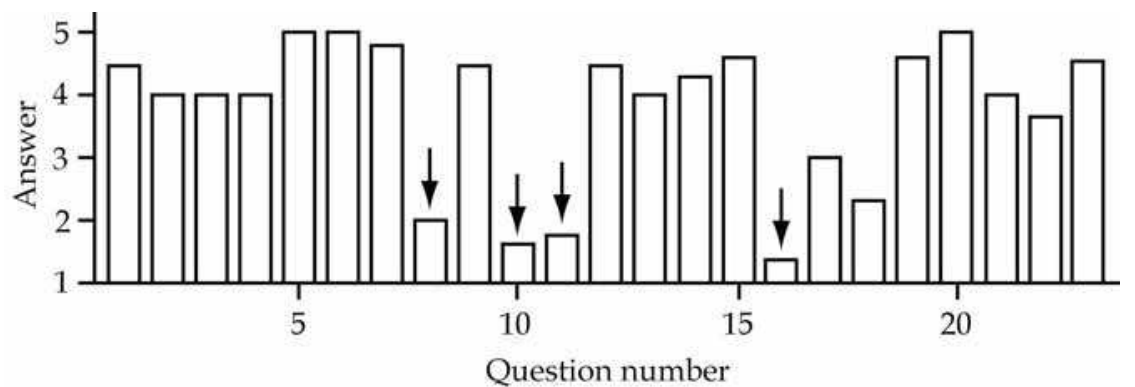

Fig. 10. Mean value of the questions from the custom made questionaire.

The only questions with negative results were 16 and 17, all of them concerning the practical sessions not related to project development. Special effort has been focused on this point, and noticeable improvement has been achieved, including the PBL structure in the laboratory sessions. However, there is still room for improvement in this aspect.

One special comment must be made concerning question number 20. This was "I feel that I am learning", with a mean result of 4.5 over 5 . This represents one of the most important items of active learning. This appreciation can furthermore be supported by means of the students' explicit opinion.

Together with the questionnaire, the students were asked to write down their opinion about several aspects of the course, such as matter treatment, course contents, what may be improved and so on. The most frequent statement refers to group working as the best aspect in the course.

The transcript of other significant answers (translated from Spanish) to some significant positive and negative questions is listed in the following.

Positive comments:

"Group working and having to argue questions, is a very correct methodology".

"The assessment is not only based upon a final exam".

"The course treatment is good, one can learn. Moreover, it is different to other courses".

"I'm surprised about the way in which the questions are solved in a whole group discussion at the end".

"Group working makes us think and argue, and that is engineering".

"Working day by day is very helpful in order to assimilate concepts".

"Having to search for information in order to answer the questions makes me to learn more". 
"Having to solve questions in groups about the subject we are working on makes us reflect. Also, the developing of projects helps us obtain a deep Negative comments understanding".

"We have too much work to do".

"It would be better to devote more time to the latest technologies".

"Practical sessions with old equipment are boring".

"Sessions are too long".

With regard to the positive comments, students really become aware of the benefits of group working. This fact is really encouraging. It is also noticeable, as well as expected, that students prefer assessment schemes that are not based upon a final exam. Students are able to feel the benefits of team working and associate this fact with doing engineering. They are also being conscious of their own learning.

One of the most repeated negative comments refers to the amount of work required. Students are used to working under conventional passive environments, on the basis of lectures. It is therefore not strange to find students commenting about this. Another interesting sentence makes reference to contents and state of the art. Due to the speed in which technology is changing, this problem is difficult to solve. Notwithstanding, this particular question was debated with students at the beginning of the course to make them decide between technological fundamentals or state of the art. The last noticeable aspect refers to practical sessions. Despite the effort made to improve their acceptance, we have still to rectify this issue. Part of the laboratory work is performed with VHS recorder training machines and almost all the negative opinions about the laboratory sessions are about this.

\subsection{Migration results}

Working close with other colleagues provides an optimum way to compare benefits and drawbacks of each one's approach to the courses' design. The resulting communication channel generates the necessary feedback to get the best of every design and to avoid, when possible, negative experiences. In this frame, the methodology adaptation process carried out in the Video Engineering course during the last four years has generated a considerable amount of single activity and sequences of activities. To date, the activity migration process takes place unidirectionally, from Video Engineering to other courses. This is due, at least partially, to having in mind the possibility of migration as one of the design basis. The courses currently using activities from Video Engineering are Digital Electronics (first year compulsory course in Telecommunication Technical Engineering), Broadcast and Cable Television (third year optional course in Telecommunication Technical Engineering) and Multimedia Techniques (third year optional course in Computer Science).

Migration of minor activities has presented two cases. On the one hand, the activity has been adapted exactly in the way it was originally designed. This is the case of the first session activity presented in section 5.1.1. The same activity is performed in the first session of Digital Electronics trying to motivate first year students at the beginning of their university learning process. Moreover, developing the same activity in the first and in the last course generates an interesting tool to compare how students' concept of engineering changes through their university process. On the other hand, some activities have been 
adapted in content but maintained in methodology. For instance, activities based on hand made posters (Figure 11) have also been integrated in the Digital Electronics course.
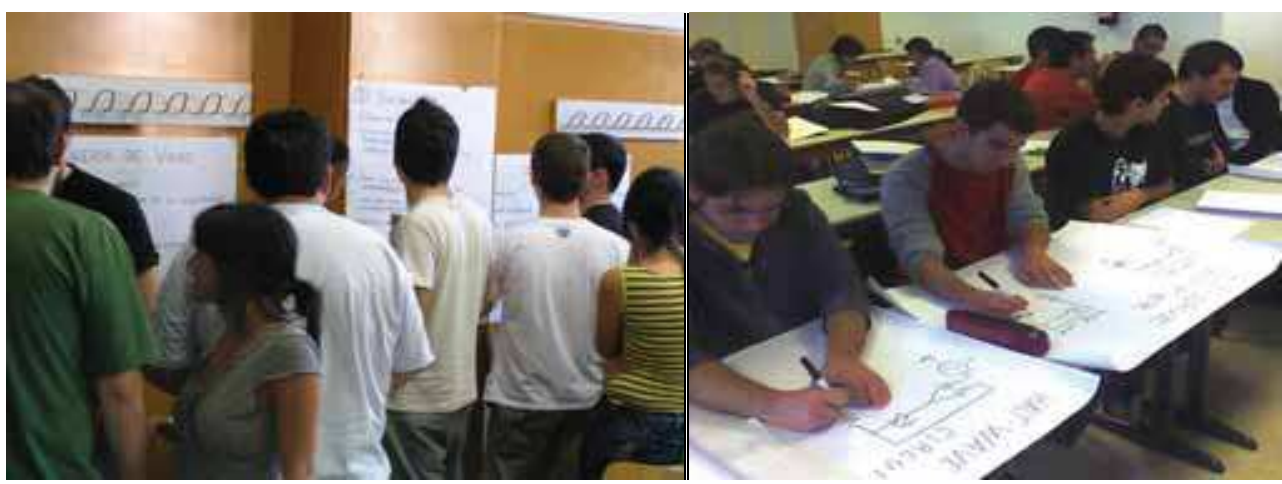

Fig. 11. Image of a minor activity in Video Engineering (left), and the equivalent one after the migration to Digital Electronics (right).

Major activities have been quite easy to export to other courses thanks to the working guide model used in the projects. Thus, both Multimedia Technology and Broadcast and Cable Television are currently set up on the basis of the major activities designed for Video Engineering. In the case of the first one, the whole course presents a very similar structure to Video Engineering, using the minor and major activities scheme and timing. The second one adopts the major activity design in the final part of the course. Figures 12 and 13 show the developing of poster session and presentation activity in the three implied courses. In both cases the same model for the guiding document has been provided to students (even with similar timing). In the Broadcast and Cable Television course, each working group was developing a different project, which is the only markable difference between courses.

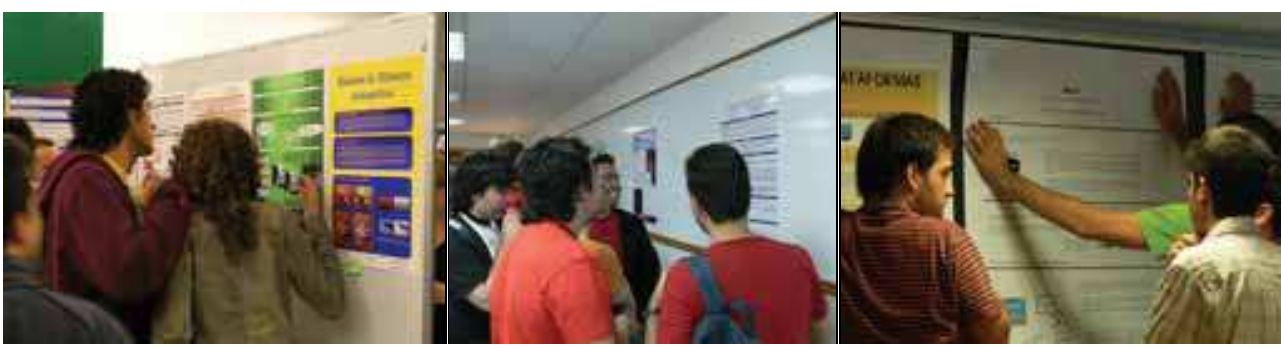

Fig. 12. Image of a poster based activity in Video Engineering (left), and the equivalent ones after the migration to Multimedia Technology (centre) and to Broadcast and Cable Television (right).

One more course is now being developed with the major activities base: Audiovisual Advanced Systems (third year optional course in Telecommunication Technical Engineering). Moreover, working groups plays the teacher role as they have to present one of the course subjects to the rest of the class. 


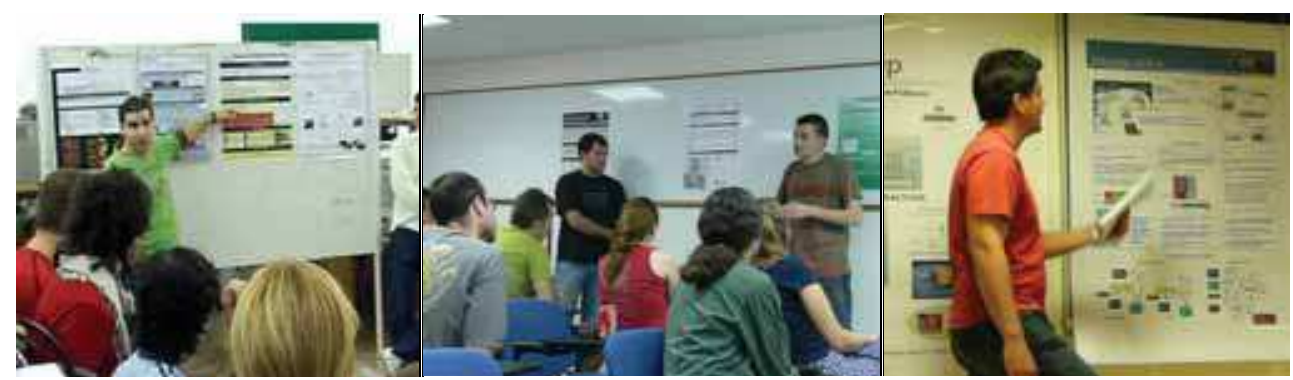

Fig. 13. Image of a conference-like presentation activity in Video Engineering (left), and the equivalent ones after the migration to Multimedia Technology (center) and to Broadcast and Cable Television (right).

In respect to the assessment-related activities, Audiovisual Advanced Systems and Multimedia Technology courses are using the peer-assessment in the same way it has been designed for Video Engineering.

\section{Conclusion}

Active learning schemes used in engineering courses have been widely proved to provide many benefits in the learning process. One of the most remarkable improvements is its efficiency in making students become conscious of learning. The high number of students who agreed to the question "I feel that I am learning", as shown in the course evaluation test, supports this statement.

When students feel they really are responsible for their own learning, their approach to learning activities is carried out maturely. When students are involved in the process of course design, stating objectives and contents, and actively being involved in assessment activities, there is no necessity to motivate them. Students' motivation can be seen through analysing their attitude, comments, academic results and low abandon rates. These results are encouraging after comparing them with the ones of other courses, with a high degree of students failing and abandoning the course prior to its ending.

If the activity design process is carried out focusing on general engineering aspects, and finally specified to one particular subject, such as video engineering, it makes the migration to other disciplines easy. Most of the activities and sequence of activities designed in the context of video engineering have been easily transferred to other engineering disciplines.

Allowing students to play the role of teacher means a step forward towards deep and lasting learning. Academic results have been remarkably improved both in mean value and in deviation. The lower the deviation the improvement between students has been more extended. The extended use of teaching as a learning activity supposes the most robust improvement in the final results.

\section{References}

Elmendorf, H. (2006). Learning through teaching: A new perspective on entering a discipline. Change, Vol. 38, No. 6, (November/December 2006) 37-41 
Graves, F. P. (1922). A student's history of education, Macmillan, New York

Grzega, J. (2006). Developing more than just linguistic competence. The model LdL for teaching foreign languages with a note on basic global English. Humanising language teaching, Vol. 8, No. 5, (September 2006). On-line magazine available on http://www.hltmag.co.uk

Johnson, D. W., Johnson R. T. \& Smith, K. A. (1991). Active learning: cooperation in the college classroom, Interaction book company, ISBN 978-0939603145, Minnesota, U.S.A.

Martin, J. P. (2002). Lernen durch Lehren (LdL). Die Schulleitung - Zeitschrift für pädagogische Führung und Fortbildung in Bayern, Vol. 4, No. 29, (December 2002) 3-9

Monroe, P. (1915). A Cyclopedia of Education, Macmillan, New York, U.S.A.

Querrin, A. (2005). L'école mutuelle: une pédagogie trop efficace?, Empêcheurs de penser en rond, ISBN 9782846711333, Paris

Race, P. (2005). Making Learning Happen. A guide for post-compulsory education, SAGE publications Ltd., ISBN 9781412907095, London

Romá, M. (2008). Can the students state the objectives of the course they are going to take?, Proceedings of 8th International Workshop on Active Learning in Engineering - ALE2008, pp. 19-28, ISBN 9799586953412, Bogotá, Colombia, June 2008, Ediciones Uniandes, Bogotá

Rusczyk, R. (2008). Learning through teaching. Art of problem solving, Avalaible on-line on http://www.artofproblemsolving.com/Resources/AoPS_R_a_Teaching.php (last seen on March 2009)

Skinner, J. (2002). The Kolbenz Model within Anglo-American Cultural Studies at German Universities, IATEFL 2002 York Annual Conference Selections, pp. 57-58, ISBN 1901095118, March 2002, IATFEL, Kent

Woods, D. R. (1994). Problem based learning: How to gain the most from PBL, McMaster University, ISBN 9780969872504, Ontario 


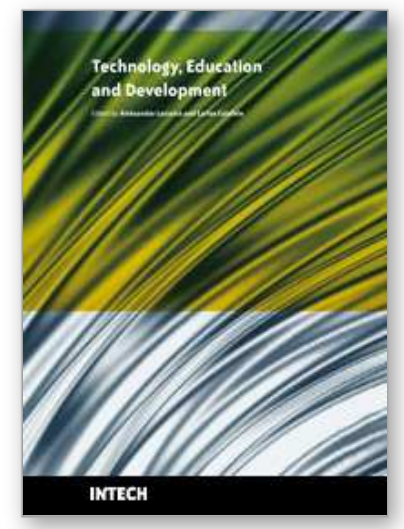

\author{
Technology Education and Development \\ Edited by Aleksandar Lazinica and Carlos Calafate
}

ISBN 978-953-307-007-0

Hard cover, 528 pages

Publisher InTech

Published online 01, October, 2009

Published in print edition October, 2009

The widespread deployment and use of Information Technologies (IT) has paved the way for change in many fields of our societies. The Internet, mobile computing, social networks and many other advances in human communications have become essential to promote and boost education, technology and industry. On the education side, the new challenges related with the integration of IT technologies into all aspects of learning require revising the traditional educational paradigms that have prevailed for the last centuries. Additionally, the globalization of education and student mobility requirements are favoring a fluid interchange of tools, methodologies and evaluation strategies, which promote innovation at an accelerated pace. Curricular revisions are also taking place to achieved a more specialized education that is able to responds to the society's requirements in terms of professional training. In this process, guaranteeing quality has also become a critical issue. On the industrial and technological side, the focus on ecological developments is essential to achieve a sustainable degree of prosperity, and all efforts to promote greener societies are welcome. In this book we gather knowledge and experiences of different authors on all these topics, hoping to offer the reader a wider view of the revolution taking place within and without our educational centers. In summary, we believe that this book makes an important contribution to the fields of education and technology in these times of great change, offering a mean for experts in the different areas to share valuable experiences and points of view that we hope are enriching to the reader. Enjoy the book!

\title{
How to reference
}

In order to correctly reference this scholarly work, feel free to copy and paste the following:

Miguel Roma (2009). Learning by Teaching in Engineering: a Step beyond Learning by Doing, Technology Education and Development, Aleksandar Lazinica and Carlos Calafate (Ed.), ISBN: 978-953-307-007-0, InTech, Available from: http://www.intechopen.com/books/technology-education-and-development/learning-byteaching-in-engineering-a-step-beyond-learning-by-doing

\section{INTECH}

open science | open minds

\section{InTech Europe}

University Campus STeP Ri

Slavka Krautzeka 83/A

51000 Rijeka, Croatia

Phone: +385 (51) 770447

Fax: +385 (51) 686166

\section{InTech China}

Unit 405, Office Block, Hotel Equatorial Shanghai

No.65, Yan An Road (West), Shanghai, 200040, China

中国上海市延安西路65号上海国际贵都大饭店办公楼 405 单元

Phone: +86-21-62489820

Fax: +86-21-62489821 
www.intechopen.com 
(C) 2009 The Author(s). Licensee IntechOpen. This chapter is distributed under the terms of the Creative Commons Attribution-NonCommercial-ShareAlike-3.0 License, which permits use, distribution and reproduction for non-commercial purposes, provided the original is properly cited and derivative works building on this content are distributed under the same license. 